\title{
The Ribosome Under Synchrotron Light
}

\author{
Venki Ramakrishnan ${ }^{\mathrm{a}, \mathrm{b}}$, Mejd Alsari, ${ }^{\mathrm{c}^{*}}$
}

In this interview Venki Ramakrishnan reviews part of his work on the structural resolution of the ribosome, for which he was jointly awarded the Nobel Prize for Chemistry in 2009. He discusses the role that synchrotron facilities have played in unravelling the structure of the ribosome and how cryogenic electron microscopy (cryo-EM) has become an essential tool for structural biologists. He concludes with an overview on his current research activities at the MRC Laboratory of Molecular Biology. See full interview at: https://youtu.be/8PIucfdIcsg.

\section{Ribosome and Antibiotics}

Mejd Alsari (MA). You've played a key role in understanding the structure of the ribosome for which you were awarded the Nobel Prize for Chemistry in 2009 together with Ada Yonath and Thomas Steitz. ${ }^{1}$ How would you explain the ribosome movie to the general scientific community and what was your contribution to achieving that understanding?

Venki Ramakrishnan (VR). If you ask the average non molecular biologist, even a scientist, even people from the physics community, what a ribosome is, almost nobody knows what a ribosome is. This always struck me as very surprising because everybody thinks they know what a gene is. If you ask someone what genes are, they say "Yes we know what genes are. They are things that give us the characteristics we inherited from our parents and pass them on to our children". But when you ask them "Well, what exactly are genes?", most of them will not be able to tell you. Even most scientists will not actually be able to tell you.

The reality is that genes are units of information. Each gene contains information for how to make a particular protein or how to regulate the making of a protein (to make more of it or less of it and so on). ${ }^{2,3}$ These instructions are encoded in our genetic material, which is a long molecule called DNA. ${ }^{4-6}$ In the DNA molecule there are hundreds of genes, which are represented as different sections within the DNA itself. Each section that contains a gene, contains information on how to make a particular protein or how to regulate it.

This can be regarded as a large library of information representing our genetic material. Now, if you were to go to the British Library and say "I want to borrow that book", they will not let you because that book is usually too valuable, it is original. Instead they will make a copy of the book, which you can read, learn from it, or carry out instructions from it, and so on.

The cell does something very similar. Although the genetic information is stored in DNA, each gene is copied into a molecule called messenger RNA (mRNA) ${ }^{7-10}$ because it carries the genetic message. The mRNA goes from the nucleus to the cytoplasm of the cell. There, a large molecular machine - the ribosome - reads this genetic message and then, based on the instructions, stitches together a protein. ${ }^{2,11-17}$ A protein is a long polymer like DNA, but unlike DNA it is only single-stranded instead of double-stranded. Whereas DNA consists of four types of bases, a protein consists of 20 types of amino acids. So it is a completely different sort of polymer. This process is called translation because you are going from the language of DNA, which is like a sentence with only four letters in the alphabet, to a different kind of polymer, which has 20 letters in its alphabet. What the ribosome does is right at the crossroads

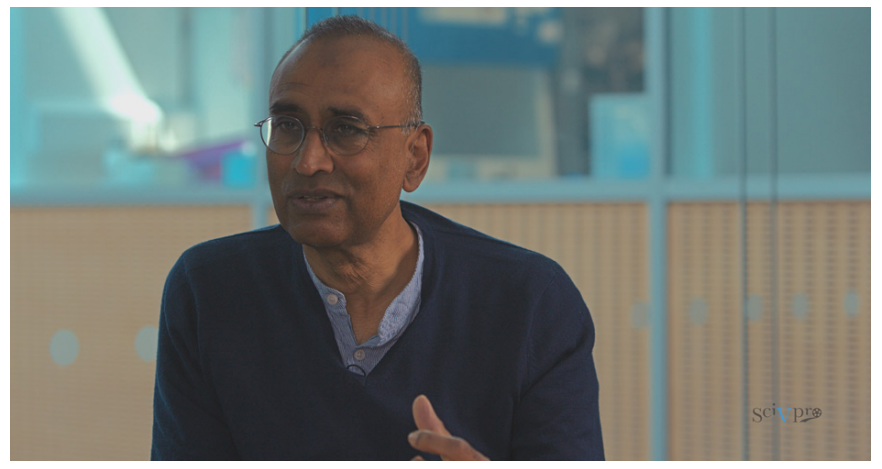

Figure 1 | Figure 1| "The Ribosome is an enormously complex molecule. To understand how it works you need to understand its structure. That was a long complicated effort. From there it was then possible to understand some of the key functional mechanisms. Because of that the Nobel Prize in 2009 was awarded to three groups.", Venki Ramakrishnan.

of biology, it is the bridge between genes and the information they contain to making the products that are specified by the gene.

Now, you asked what my contribution was. Ribosomes were discovered in the $1950 \mathrm{~s},{ }^{18}$ but they are enormously complex molecules. It is almost not correctly regarded as a molecule because it is an assembly of 80 or so molecules and it is about half a million atoms. So it is incredibly complicated. To understand how it works, just as with any other molecule, you want to know what it looks like, how it interacts with the genetic message, how it stitches together amino acids to make a protein, how it moves, etc. To do that you need to understand its structure, you need to be able to visualize what the ribosome actually looks like, and not just in one state, but what does it look like as it is carrying out its function. That was a long complicated effort, which required several groups to determine its high resolution structure. From there it was then possible to understand some of the key functional mechanisms, such as how it reads the genetic code accurately and how it makes the peptide bond, which is the bond between amino acids. ${ }^{19}$ Because of that the Nobel Prize in 2009 was awarded to three groups. ${ }^{1,20}$ More than three groups actually contributed to the effort, but in terms of the high resolution structure, I think these were the three groups that actually made the breakthroughs.

MA. Could you explain how your research is important for antibiotics and what are the key challenges in developing new antibiotics for super-bacteria? ${ }^{21}$

VR. As we all know, the resistance to antibiotics, antimicrobial resistance, is a huge problem. In fact, about 25,000 people die in just 
Europe as a result of resistant infections. ${ }^{22}$ When you look at the antibiotics that are available, almost half of them target the ribosome or the protein synthesis machinery. Now it turns out that because the ribosomes are so old, they have diverged between bacteria and us. Even in the core functional areas there are sufficient differences between our ribosomes and bacterial ribosomes. The result is there is a class of compounds that can bind to bacterial ribosomes and stop them from working, but they do not bind to our ribosomes. ${ }^{23}$ For this reason a number of antibiotics are useful to treat bacterial infections. ${ }^{24-27}$

After the structures of the ribosome were resolved, it was then straightforward to determine the structure of the ribosome with various antibiotics bound. That part became just a straightforward extension of the original structure. So for the first time we could visualize in atomic detail how these antibiotics bound to the ribosome. ${ }^{12,13,28-33}$ That not only allowed us to understand how these antibiotics worked but it also to understand why resistance would occur. For example, with a certain mutation, why these antibiotics would not work, or if the antibiotics were modified by some resistance mechanism. ${ }^{32,33}$

MA. You also have a paper detailing the structure of the 70 s with the antibiotic ${ }^{34} \ldots$

VR. Yes, but there are several structures. The most cited paper is our original paper on the 30s, which was published in 2000 . $^{32}$ The high-resolution structure of the entire ribosome came later and it was actually Tom Steitz's lab at Yale who used that structure to determine a number of antibiotic structures..$^{12,13,28-31}$ Regarding the development of new antibiotics, many drug companies, including one that was started by Tom Steitz, Peter Moore, and others at Yale, have been trying to use these structures to design better antibiotics. ${ }^{35}$

However, this is not just a technical problem, it is also a business and economic problem. The issue with the development of new antibiotics is that if you develop a new antibiotic you typically want to give it to patients for whom the standard antibiotics do not work. These standard antibiotics are a lot cheaper, they have been around awhile, they are generic, and so on. So the patient pool is actually quite small. Moreover, if you give an antibiotic to a patient, the patient is typically cured in a week or so, if the antibiotic is any good. Therefore, this is not a model for making a lot of profit. As a result, there has been almost no new class of antibiotics for almost 20 years. This is because drug companies do not see this as a big profit-making venture because they have to spend a huge amount of time first of all finding compounds. But even if they find a compound, it is very expensive to carry it through all the clinical trials and get approval for it to be a drug. Some estimate that it costs about a billion dollars to develop a new medicine. ${ }^{38}$ So they do not necessarily see

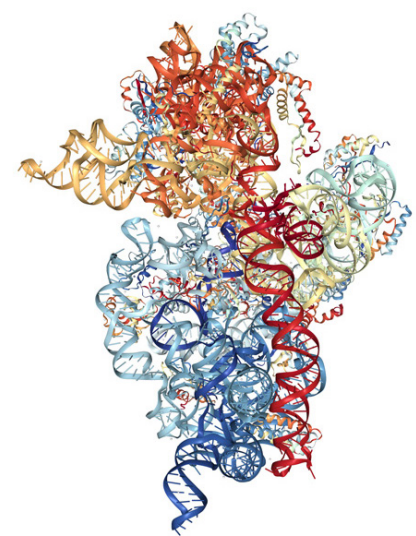

Figure 2 | Structure of the Thermus thermophilus 30 S Ribosomal Subunit. Readapted from Wimberly et. $\mathrm{al}^{36}$ ( DOI: 10.2210/pdb1J5E/pdbEntry 1J5E supersedes 1FJFNDB: RR0052) with the NGL viewer. ${ }^{37}$

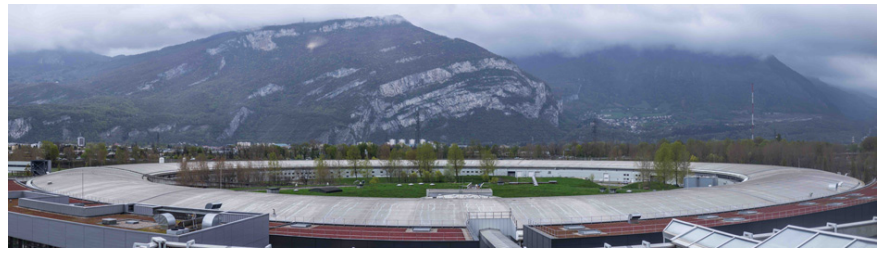

Figure 3 | The European Synchrotron Radiation Facility (ESRF, France).

guarantee of a return on that sort of investment. I believe that the problem needs to be tackled somewhat differently and what we must remember is one of the first big antibiotics was penicillin. Penicillin was developed by a huge government initiative at Oxford during World War II. ${ }^{21,39}$ Therefore there is no reason why governments, multinational organizations, or big charities cannot get involved in antibiotic development as was originally done with penicillin.

\section{Synchrotron Light}

MA. In your book you extensively discussed the importance of correctly crystallizing the ribosomal subunits. ${ }^{40-45}$ What approaches did you take in order to extract the ribosomal subunits and crystallize them? What is the current state-of-the-art?

VR. We were somewhat fortunate in that we got initial crystals while trying to reproduce crystals that had been reported by a Russian group in the mid-1980s. ${ }^{46}$ But then we looked at these crystals, analysed them, and realized that these crystals were lacking a protein that was present in variable amounts in the ribosome. We removed this variable component completely so that we had very pure homogeneous particles and then we slowly crystallized them at $4^{\circ} \mathrm{C}$ in the cold room. We also made sure that there were not any contaminants that could degrade the particles while they were slowly crystallizing over several weeks. Some of them took about eight weeks to grow to full size. I think that is what really gave us very good crystals. I think it was a bit of luck and a bit of being very careful with our sample preparation. There was no magic in it. ${ }^{47-49}$

MA. That brings us to synchrotron light. ${ }^{50,51}$ Can you explain what has been the role of synchrotron light in achieving our current understanding of the ribosome structure and what are the current experimental workflows?

VR. Any time until about 2011-2012 it would have been impossible to solve the structure of the ribosome without a synchrotron. Because the only technique that was capable of producing an atomic structure up to about 2012 was by X-ray crystallography. If you took a normal laboratory-based X-ray source, like a rotating anode, it simply does not have the coherence or the intensity to produce high resolution diffraction from crystals of the ribosome because the diffraction from ribosome crystals is too weak. This is because a ribosome is such a large molecule that the unit cell that is the repeating unit in the crystal is very large. Therefore, for a crystal of a given size there are fewer unit cells. Because the ribosome molecule is very large and there are very few points of contact, the ribosome crystal has lots of solvent channels, mostly water, between the crystals. Our small subunit crystals were about $70-75 \%$ water and only $25 \%$ ribosomes actually. This makes these crystals very weakly diffracting. For this reason, you needed synchrotrons.

The other reason for using synchrotrons is that the way we determined the structure was by tuning the wavelength. Certain special atoms in the structure would stand out. It is a technique called anomalous scattering. ${ }^{48,52-55}$ That again required synchrotrons, because with synchrotrons you can fine-tune X-rays wavelength very precisely.

These two things meant that synchrotrons were indispensable for solving the structure. That is no longer true. Today if you wanted to solve a ribosome structure you would not actually even go to synchrotron at all. What you would do is use a technique called 
cryo-electron microscopy, a lot of which was developed here at the MRC Laboratory of Molecular Biology by Richard Henderson and his colleagues, for which Richard Henderson shared the 2017 Nobel Prize in Chemistry. ${ }^{56-58}$

MA. You have done work at a number of synchrotrons and one of them is the ESRF. ${ }^{59}$ Could you talk about your work there, what beamline you have used, and if you still apply for beamtime there?

VR. I have used several beamlines at the ESRF. Most of them have the property that they are undulator beamlines, which are typically prefixed with ID for insertion device. ${ }^{60,61}$ These beamlines have very high intensity and high coherence, which is what you need to get data of sufficiently good quality from ribosome crystals. We used to use ID14 quite a lot in the old days, then ID29 came along, and now there are other beamlines as well. ${ }^{62}$ We have also used the Swiss Light Source ${ }^{63}$ and notably we use the APS, the Advanced Photon Source at Argonne National Lab ${ }^{64}$ which gave us our initial phases for the 30s subunit. All of these synchrotrons have the same sort of characteristics, i.e. insertion devices to produce very high intensity in a very highly parallel coherent beam. I have not applied for synchrotron beamtime since about 2012 because my lab no longer primarily uses crystallography. In fact, we have not done any crystallography for almost six or seven years. That is because we have shifted to cryo-electron microscopy. ${ }^{56}$

\section{Current Work}

MA. What about looking at the evolution of a sample? Could you talk about the opportunities and challenges with in-situ and in-vivo studies?

VR. I think in-vivo studies are mostly limited to light microscopy because light does not damage the molecule and you can visualize various parts of the cell. Now there is a technique called super-resolution microscopy, ${ }^{65-67}$ which allows you to label specific molecules inside the cell, see them at quite high resolution, and see where their distribution is. So, you can watch things happening in the cell, while the cell is alive. Or sometimes you allow the cell to reach a certain stage and then you fix it.

In terms of high resolution, the way to do it is to attempt trapping the cell in different stages, then freeze it, and then look at it. This is a technique in electron microscopy called tomography, ${ }^{68-71}$ which allows you to look at entire cells, look at where molecules are inside cells, and even obtain structure of molecular complexes inside the cell as they exist. That would not be called exactly in-vivo because the cell is not really alive, but you could call it in-situ because it is as it exists inside the cell.

MA. Could you tell us a bit about what your research group is working on at the moment and what is the scientific question you're trying to answer?

VR. We are still working on ribosomes because it is often the case in research that when you make a breakthrough it is not the end of the road. All it does is raise a completely different set of questions. There is no sort of end point in science or at least not in most things. What we are looking at is how ribosomes know where to start reading the message. ${ }^{72,73}$ The way that is done is very different in bacteria and in human ribosomes or in yeast ribosomes. Yeast and us have more similarity because we are what are called eukaryotes, where cells contain a nucleus. ${ }^{74-77}$ Our ribosomes are more similar than those of bacteria. We are understanding this process called initiation, ${ }^{78}$ which involves a number of proteins that come and bind to the messenger RNA and to the small ribosomal subunit to bring it to the right starting point, where it can begin translating the gene and making the protein. It is a highly regulated process and when it is deregulated it can lead to things like cancer. Moreover, there are viruses that can hijack this initiation process by having their own kind of machinery that does not require all these protein factors from the cell. The result is that all of the translation is diverted to translating the virus's own genes. So, it is a way for the virus to stop the ribo- some from making the host proteins and start making the viruses proteins instead. ${ }^{79}$ This is a very interesting problem and some of our effort is focused on that.

We also have organelles in us called mitochondria, which are remnants of bacteria that were swallowed up by another cell about two billion years ago. ${ }^{14,80-83}$ Although they have been in us for two billion years they still retain a small genome and for that they have their own ribosomes (mitoribosomes), which translate their genes. ${ }^{83,84}$ These ribosomes have differentiated quite a lot from both bacterial ribosomes and from our own ribosomes. ${ }^{85,86}$ So, they are interesting biologically. They are also important medically. ${ }^{87-89} \mathrm{In}$ fact many antibiotics are toxic as they bind to our mitochondrial ribosomes because they are sort of descendants of bacteria; they are bacteria-like in some respects. Antibiotics that normally might not be so toxic end up being toxic because they bind to our mitochondrial ribosomes. ${ }^{24}$ So, it is important to understand their structure for that reason and many genetic diseases map to mitochondrial ribosomes. ${ }^{23,88,90}$ We solved the structure of mitochondrial ribosomes along with Nenad Ban's lab in Zürich. ${ }^{74-77,83,91,92}$ We were to some extent competitors, not collaborators, but friendly competitors. ${ }^{23}$ These structures are now paving the way for understanding how mitochondrial ribosomes work and possibly how mutations in them might cause various diseases. That is another area.

Finally, we are trying to understand how cells are regulating translation. ${ }^{93-99}$ If ribosomes get stuck, how does a cell rescue ribosome and regulate the whole process of translation and maintain quality control? How does it know when things are have gone awry, when you need to stop translation and start again? These are sort of some of the areas we are working on.

\section{References}

1 The Nobel Prize in Chemistry 2009, https://www.nobelprize.org/prizes/chemistry/2009/summaryl, (2009).

2 T. M. Schmeing \& V. Ramakrishnan. What recent ribosome structures have revealed about the mechanism of translation. Nature 461, 1234, (2009).

3 T. A. Steitz. A structural understanding of the dynamic ribosome machine. Nature Reviews Molecular Cell Biology 9, 242, (2008).

4 J. D. Watson \& F. H. C. Crick. Molecular Structure of Nucleic Acids: A Structure for Deoxyribose Nucleic Acid. Nature 171, 737-738, (1953).

5 F. Crick. Central Dogma of Molecular Biology. Nature 227, 561-563, (1970).

6 J. D. Watson \& F. H. C. Crick. Genetical Implications Of The Structure Of Deoxyribonucleic Acid. JAMA 269, 1967-1969, (1993).

7 S. Brenner, F. Jacob \& M. Meselson. An Unstable Intermediate Carrying Information from Genes to Ribosomes for Protein Synthesis. Nature 190, 576-581, (1961).

8 F. Gros, H. Hiatt, W. Gilbert, C. G. Kurland, R. W. Risebrough \& J. D. Watson. Unstable Ribonucleic Acid Revealed by Pulse Labelling of Escherichia Coli. Nature 190, 581-585, (1961).

9 F. Jacob \& J. Monod. Genetic regulatory mechanisms in the synthesis of proteins. Journal of Molecular Biology 3, 318-356, (1961).

10 M. Cobb. Who discovered messenger RNA? Current Biology 25, R526-R532, (2015).

11 J. M. Ogle, D. E. Brodersen, W. M. Clemons, M. J. Tarry, A. P. Carter \& V. Ramakrishnan. Recognition of Cognate Transfer RNA by the 30S Ribosomal Subunit. Science 292, 897, (2001).

12 P. Nissen, J. Hansen, N. Ban, P. B. Moore \& T. A. Steitz. The Structural Basis of Ribosome Activity in Peptide Bond Synthesis. Science 289, 920, (2000).

13 N. Ban, P. Nissen, J. Hansen, P. B. Moore \& T. A. Steitz. The Complete Atomic Structure of the Large Ribosomal Subunit at $2.4 \AA$ Resolution. Science 289, 905, (2000).

14 A. A. Pittis \& T. Gabaldón. Late acquisition of mitochondria by a host with chimaeric prokaryotic ancestry. Nature 531, 101, (2016).

15 M. Beringer \& M. V. Rodnina. The Ribosomal Peptidyl Transferase. Molecular Cell 26, 311-321, (2007).

16 S. Jenni \& N. Ban. The chemistry of protein synthesis and voyage through the ribosomal tunnel. Current Opinion in Structural Biology 13, 212-219, (2003). 
17 G. Kramer, D. Boehringer, N. Ban \& B. Bukau. The ribosome as a platform for co-translational processing, folding and targeting of newly synthesized proteins. Nature Structural \&Amp; Molecular Biology 16, 589, (2009). G. E. Palade. A Small Particulate Component Of The Cytoplasm. The Journal of Biophysical and Biochemical Cytology 1, 59, (1955).

19 R. M. Voorhees \& V. Ramakrishnan. Structural Basis of the Translational Elongation Cycle. Annual Review of Biochemistry 82, 203-236, (2013).

V. Ramakrishnan. Unraveling the Structure of the Ribosome (Nobel Lecture). Angewandte Chemie International Edition 49, 4355-4380, (2010).

21 C. L. Ventola. The antibiotic resistance crisis: part 1: causes and threats, $\underline{\text { https:// }}$ www.ncbi.nlm.nih.gov/pmc/articles/PMC4378521/, (2015).

22 J. M. A. Blair, M. A. Webber, A. J. Baylay, D. O. Ogbolu \& L. J. V. Piddock Molecular mechanisms of antibiotic resistance. Nature Reviews Microbiology 13, 42, (2014).

23 B. J. Greber \& N. Ban. Structure and Function of the Mitochondrial Ribosome. Annual Review of Biochemistry 85, 103-132, (2016). D. N. Wilson. Ribosome-targeting antibiotics and mechanisms of bacterial resistance. Nature Reviews Microbiology 12, 35, (2013). gy 1, 65-70, (2003)

J. Poehlsgaard \& S. Douthwaite. The bacterial ribosome as a target for antibiotics. Nature Reviews Microbiology 3, 870-881, (2005).

27 D. N. Wilson. The A-Z of bacterial translation inhibitors. Critical Reviews in Biochemistry and Molecular Biology 44, 393-433, (2009).

28 J. L. Hansen, J. A. Ippolito, N. Ban, P. Nissen, P. B. Moore \& T. A. Steitz. The structures of four macrolide antibiotics bound to the large ribosomal subunit. Molecular cell 10, 117-128, (2002).

D. Tu, G. Blaha, P. B. Moore \& T. A. Steitz. Structures of MLSBK Antibiotic Bound to Mutated Large Ribosomal Subunits Provide a Structural Explanation for Resistance. Cell 121, 257-270, (2005).

30 J. L. Hansen, P. B. Moore \& T. A. Steitz. Structures of Five Antibiotics Bound at the Peptidyl Transferase Center of the Large Ribosomal Subunit. Journal of Molecular Biology 330, 1061-1075, (2003).

31 J. A. Ippolito, Z. F. Kanyo, D. Wang, F. J. Franceschi, P. B. Moore, T. A. Steitz \& E. M. Duffy. Crystal Structure of the Oxazolidinone Antibiotic Linezolid Bound to the 50S Ribosomal Subunit. Journal of Medicinal Chemistry 51, 3353-3356, (2008).

32 A. P. Carter, W. M. Clemons, D. E. Brodersen, R. J. Morgan-Warren, B. T. Wimberly \& V. Ramakrishnan. Functional insights from the structure of the 30 S ribosomal subunit and its interactions with antibiotics. Nature 407, 340 (2000)

33 D. E. Brodersen, W. M. Clemons, A. P. Carter, R. J. Morgan-Warren, B. T. Wimberly \& V. Ramakrishnan. The Structural Basis for the Action of the Antibiotics Tetracycline, Pactamycin, and Hygromycin B on the 30S Ribosomal Subunit. Cell 103, 1143-1154, (2000)

34 M. Selmer, C. M. Dunham, F. V. Murphy, A. Weixlbaumer, S. Petry, A. C. Kelley, J. R. Weir \& V. Ramakrishnan. Structure of the 70S Ribosome Complexed with mRNA and tRNA. Science 313, 1935, (2006).

35 Melinta Therapeutics, https://melinta.com/, (2009).

36 B. T. Wimberly, D. E. Brodersen, W. M. Clemons, R. J. Morgan-Warren, A. P. Carter, C. Vonrhein, T. Hartsch \& V. Ramakrishnan. Structure of the $30 \mathrm{~S}$ ribosomal subunit. Nature 407, 327-339, (2000).

37 A. S. Rose, A. R. Bradley, Y. Valasatava, J. M. Duarte, A. Prlić \& P. W. Rose NGL viewer: web-based molecular graphics for large complexes. Bioinformatics 34, 3755-3758, (2018).

38 A. Towse, C. K. Hoyle, J. Goodall, M. Hirsch, J. Mestre-Ferrandiz \& J. H. Rex. Time for a change in how new antibiotics are reimbursed: Development of an insurance framework for funding new antibiotics based on a policy of risk mitigation. Health Policy 121, 1025-1030, (2017).

39 R. Hare. New light on the history of penicillin. Medical History 26, 1-24, (2012).

40 V. Ramakrishnan. The Gene Machine: The Race to Decipher the Secrets of the Ribosome. (2018).

41 P. N. T. Unwin \& C. Taddei. Packing of ribosomes in crystals from the lizard Lacerta sicula. Journal of Molecular Biology 114, 491-506, (1977).

42 K. von Böhlen, I. Makowski, H. A. S. Hansen, H. Bartels, Z. Berkovitch-Yellin,
A. Zaytzev-Bashan, S. Meyer, C. Paulke, F. Franceschi \& A. Yonath. Characterization and preliminary attempts for derivatization of crystals of large ribosomal subunits from Haloarcula marismortui diffracting to $3 \AA$ resolution. Journal of Molecular Biology 222, 11-15, (1991).

43 A. Yonath, C. Glotz, H. S. Gewitz, K. S. Bartels, K. von Böhlen, I. Makowski \& H. G. Wittmann. Characterization of crystals of small ribosomal subunits. Journal of Molecular Biology 203, 831-834, (1988).

44 H. Hope. Cryocrystallography of biological macromolecules: a generally applicable method. Acta Crystallographica Section B 44, 22-26, (1988).

45 H. Hope, F. Frolow, K. von Bohlen, I. Makowski, C. Kratky, Y. Halfon, H. Danz, P. Webster, K. S. Bartels, H. G. Wittmann \& A. Yonath. Cryocrystallography of ribosomal particles. Acta Crystallographica Section B 45, 190-199, (1989).

46 S. D. Trakhanov, M. M. Yusupov, S. C. Agalarov, M. B. Garber, S. N. Ryazantsev, S. V. Tischenko \& V. A. Shirokov. Crystallization of $70 \mathrm{~S}$ ribosomes and $30 \mathrm{~S}$ ribosomal subunits from Thermus thermophilus. FEBS Letters 220, 319322, (1987).

47 W. M. Clemons, D. E. Brodersen, J. P. McCutcheon, J. L. C. May, A. P. Carter, R. J. Morgan-Warren, B. T. Wimberly \& V. Ramakrishnan. Crystal structure of the $30 \mathrm{~S}$ ribosomal subunit from Thermus thermophilus: purification, crystallization and structure determination11Edited by T. Richmond. Journal of Molecular Biology 310, 827-843, (2001).

48 W. M. Clemons, J. L. C. May, B. T. Wimberly, J. P. McCutcheon, M. S. Capel \& V. Ramakrishnan. Structure of a bacterial 30 S ribosomal subunit at $5.5 \AA$ resolution. Nature 400, 833-840, (1999).

49 S. Petry, D. E. Brodersen, F. V. Murphy, C. M. Dunham, M. Selmer, M. J. Tarry, A. C. Kelley \& V. Ramakrishnan. Crystal Structures of the Ribosome in Complex with Release Factors RF1 and RF2 Bound to a Cognate Stop Codon. Cell 123, 1255-1266, (2005).

50 H. Winick \& S. Doniach. Synchrotron radiation research. (Springer Science \& Business Media, 2012).

51 W. A. Hendrickson. Synchrotron crystallography. Trends in Biochemical Sciences 25, 637-643, (2000)

52 J. C. Phillips \& K. O. Hodgson. The use of anomalous scattering effects to phase diffraction patterns from macromolecules. Acta Crystallographica Section A 36, 856-864, (1980).

53 W. A. Hendrickson, J. L. Smith, R. P. Phizackerley \& E. A. Merritt. Crystallographic structure analysis of lamprey hemoglobin from anomalous dispersion of synchrotron radiation. Proteins: Structure, Function, and Bioinformatics 4, 77-88, (1988).

54 W. A. Hendrickson, J. R. Horton \& D. M. LeMaster. Selenomethionyl proteins produced for analysis by multiwavelength anomalous diffraction (MAD): a vehicle for direct determination of three-dimensional structure. The EMBO Journal 9, 1665-1672, (1990).

55 V. Ramakrishnan, J. T. Finch, V. Graziano, P. L. Lee \& R. M. Sweet. Crystal structure of globular domain of histone H5 and its implications for nucleosome binding. Nature 362, 219-223, (1993)

56 W. Kühlbrandt. The Resolution Revolution. Science 343, 1443, (2014).

57 A. R. Faruqi \& R. Henderson. Electronic detectors for electron microscopy. Current Opinion in Structural Biology 17, 549-555, (2007).

58 The Nobel Prize in Chemistry 2017, https://www.nobelprize.org/prizes/chemistry/2017/summary/, (2017).

59 European Synchrotron Radiation Facility, https://www.esrf.eu/, (2019).

60 Insertion Devices, http://www.esrf.eu/fr/home/UsersAndScience/Publications/Highlights/2003/XraySource/XraySource06.html, (2019).

61 J. Chavanne, P. Elleaume \& P. Van Vaerenbergh. The ESRF Insertion Devices. Journal of Synchrotron Radiation 5, 196-201, (1998).

62 ID29 MX Tunable Microbeam, https://www.esrf.eu/id29, (2019).

63 Swiss Light Source - SLS, https://www.psi.ch/en/sls, (2019).

64 Advanced Photon Source, https://www.aps.anl.gov/, (2019).

65 G. Shtengel, J. A. Galbraith, C. G. Galbraith, J. Lippincott-Schwartz, J. M. Gillette, S. Manley, R. Sougrat, C. M. Waterman, P. Kanchanawong, M. W. Davidson, R. D. Fetter \& H. F. Hess. Interferometric fluorescent super-resolution microscopy resolves 3D cellular ultrastructure. Proceedings of the National Academy of Sciences 106, 3125, (2009).

66 K. I. Mortensen, L. S. Churchman, J. A. Spudich \& H. Flyvbjerg. Optimized 
localization analysis for single-molecule tracking and super-resolution microscopy. Nature Methods 7, 377, (2010).

67 B. Huang, W. Wang, M. Bates \& X. Zhuang. Three-Dimensional Super-Resolution Imaging by Stochastic Optical Reconstruction Microscopy. Science 319, 810, (2008).

68 P. A. Midgley \& M. Weyland. 3D electron microscopy in the physical sciences: the development of Z-contrast and EFTEM tomography. Ultramicroscopy $\mathbf{9 6}$ 413-431, (2003).

69 J. Frank. Electron tomography. (Springer, 1992).

70 D. N. Mastronarde. Automated electron microscope tomography using robust prediction of specimen movements. Journal of Structural Biology 152, 36-51, (2005).

71 A. J. Koster, R. Grimm, D. Typke, R. Hegerl, A. Stoschek, J. Walz \& W. Baumeister. Perspectives of Molecular and Cellular Electron Tomography. Journal of Structural Biology 120, 276-308, (1997).

72 T. Hussain, J. L. Llácer, B. T. Wimberly, J. S. Kieft \& V. Ramakrishnan. LargeScale Movements of IF3 and tRNA during Bacterial Translation Initiation. Cell 167, 133-144.e113, (2016).

73 I. S. Fernández, X.-C. Bai, T. Hussain, A. C. Kelley, J. R. Lorsch, V. Ramakrishnan \& S. H. W. Scheres. Molecular Architecture of a Eukaryotic Translational Initiation Complex. Science 342, 1240585, (2013).

74 A. Amunts, A. Brown, X.-c. Bai, J. L. Llácer, T. Hussain, P. Emsley, F. Long, G. Murshudov, S. H. W. Scheres \& V. Ramakrishnan. Structure of the Yeast Mitochondrial Large Ribosomal Subunit. Science 343, 1485, (2014).

75 B. J. Greber, D. Boehringer, A. Leitner, P. Bieri, F. Voigts-Hoffmann, J. P. Erzberger, M. Leibundgut, R. Aebersold \& N. Ban. Architecture of the large subunit of the mammalian mitochondrial ribosome. Nature 505, 515, (2013).

76 B. J. Greber, D. Boehringer, M. Leibundgut, P. Bieri, A. Leitner, N. Schmitz, R. Aebersold \& N. Ban. The complete structure of the large subunit of the mammalian mitochondrial ribosome. Nature 515, 283, (2014).

77 A. Brown, A. Amunts, X.-c. Bai, Y. Sugimoto, P. C. Edwards, G. Murshudov S. H. W. Scheres \& V. Ramakrishnan. Structure of the large ribosomal subunit from human mitochondria. Science 346, 718, (2014).

78 J. L. Llácer, T. Hussain, A. K. Saini, J. S. Nanda, S. Kaur, Y. Gordiyenko, R. Kumar, A. G. Hinnebusch, J. R. Lorsch \& V. Ramakrishnan. Translational initiation factor eIF5 replaces eIF1 on the $40 \mathrm{~S}$ ribosomal subunit to promote start-codon recognition. eLife 7, e39273, (2018).

79 Israel S. Fernández, X.-C. Bai, G. Murshudov, Sjors H. W. Scheres \& V. Ramakrishnan. Initiation of Translation by Cricket Paralysis Virus IRES Requires Its Translocation in the Ribosome. Cell 157, 823-831, (2014).

80 T. M. Embley \& W. Martin. Eukaryotic evolution, changes and challenges. Nature 440, 623-630, (2006).

81 T. J. G. Ettema. Mitochondria in the second act. Nature 531, 39, (2016).

82 M. W. Gray, G. Burger \& B. F. Lang. Mitochondrial Evolution. Science 283, 1476, (1999).

83 N. Desai, A. Brown, A. Amunts \& V. Ramakrishnan. The structure of the yeast mitochondrial ribosome. Science 355, 528, (2017).

84 M. Ott, A. Amunts \& A. Brown. Organization and Regulation of Mitochondrial Protein Synthesis. Annual Review of Biochemistry 85, 77-101, (2016).

85 T. W. O'Brien. Evolution of a protein-rich mitochondrial ribosome: implications for human genetic disease. Gene 286, 73-79, (2002).

86 M. R. Sharma, E. C. Koc, P. P. Datta, T. M. Booth, L. L. Spremulli \& R. K. Agrawal. Structure of the Mammalian Mitochondrial Ribosome Reveals an Expanded Functional Role for Its Component Proteins. Cell 115, 97-108, (2003).

87 A. Rötig. Human diseases with impaired mitochondrial protein synthesis. Biochimica et Biophysica Acta (BBA) - Bioenergetics 1807, 1198-1205, (2011).

88 S. B. Vafai \& V. K. Mootha. Mitochondrial disorders as windows into an ancient organelle. Nature 491, 374, (2012).

89 S. Pearce, C. L. Nezich \& A. Spinazzola. Mitochondrial diseases: Translation matters. Molecular and Cellular Neuroscience 55, 1-12, (2013).

90 D. Skladal, J. Halliday \& D. R. Thorburn. Minimum birth prevalence of mitochondrial respiratory chain disorders in children. Brain 126, 1905-1912, (2003).

91 A. Amunts, A. Brown, J. Toots, S. H. W. Scheres \& V. Ramakrishnan. The structure of the human mitochondrial ribosome. Science 348, 95, (2015).
92 B. J. Greber, P. Bieri, M. Leibundgut, A. Leitner, R. Aebersold, D. Boehringer \& N. Ban. The complete structure of the 55\&lt;em\&gt;S\&lt;/em\&gt; mammalian mitochondrial ribosome. Science 348, 303, (2015).

93 J. M. Ogle \& V. Ramakrishnan. Structural Insights Into Translational Fidelity. Annual Review of Biochemistry 74, 129-177, (2005).

94 C. D. Rae, Y. Gordiyenko \& V. Ramakrishnan. How a circularized tmRNA moves through the ribosome. Science 363, 740, (2019).

95 S. Teichmann. Technologies to watch in 2019. Nature 565, 521-523, (2019).

96 S. Juszkiewicz, V. Chandrasekaran, Z. Lin, S. Kraatz, V. Ramakrishnan \& R. S. Hegde. ZNF598 Is a Quality Control Sensor of Collided Ribosomes. Molecular Cell 72, 469-481.e467, (2018).

97 A. Brown, S. Rathore, D. Kimanius, S. Aibara, X.-c. Bai, J. Rorbach, A. Amunts \& V. Ramakrishnan. Structures of the human mitochondrial ribosome in native states of assembly. Nature Structural \&Amp; Molecular Biology 24, 866, (2017).

98 N. R. James, A. Brown, Y. Gordiyenko \& V. Ramakrishnan. Translational termination without a stop codon. Science 354, 1437, (2016).

99 S. Shao, J. Murray, A. Brown, J. Taunton, V. Ramakrishnan \& R. S. Hegde. Decoding Mammalian Ribosome-mRNA States by Translational GTPase Complexes. Cell 167, 1229-1240.e1215, (2016).

\section{Conflicts of Interest}

There are no conflicts to declare.

\section{Acknowledgements}

M.A. thanks Khalaf Al Habtoor, chairman of Al Habtoor Group, for sponsoring the video production. M.A. also thanks the MRC Laboratory of Molecular Biology and the Royal Society for arranging the interview with V.R.

\section{Author Contributions}

V.R. was interviewed by M.A., who wrote this manuscript.

\section{Keywords}

Ribosome, antibiotics, 30s, 70s, 50s, synchrotron, ESRF, APS, SLS, cryo-electron microscopy, Nobel Prize, gene, DNA, RNA, m-RNA, cell, cytoplasm, nucleus, protein, code, information, bacteria, super-bacteria, antimicrobial resistance, drug, pharmaceutics, pharma, profit, penicillin, subunit, crystal, crystallize, crystallography, tomography, LMB, MRC Laboratory of Molecular Biology, Cambridge, mitoribosomes, mitochondria, translation, initiation, regulation.

\section{Article Information}

This article is licensed by V.R. et al. under a Creative Commons Attribution 4.0 International License (CC BY 4.0). 